\title{
Evaluation of Machinability in Turning of Engineering Alloys by Applying Artificial Neural Networks
}

\author{
Nikolaos M. Vaxevanidis ${ }^{1, *}$, John D. Kechagias ${ }^{2}$, Nikolaos A. Fountas ${ }^{1}$ and Dimitrios E. Manolakos ${ }^{3}$ \\ ${ }^{I}$ School of Pedagogical and Technological Education (ASPETE), Department of Mechanical Engineering, Laboratory of \\ Manufacturing Processes and Machine Tools (LMProMaT), ASPETE Campus, GR 14121, N. Heraklion, Greece; \\ ${ }^{2}$ Technological Educational Institute (TEI) of Thessaly, Mechanical Engineering Department, TEI Campus, GR 41110, \\ Larissa, Greece; ${ }^{3}$ National Technical University of Athens (NTUA), Department of Mechanical Engineering, Manufac- \\ turing Technology Division, Zografou NTUA Campus, GR 15780, Greece
}

\begin{abstract}
The present paper investigates the influence of main cutting parameters on the machinability during turning process for three typical materials namely AISI D6 tool steel, Ti6A14V ELI and CuZn39Pb3 brass, all three under dry cutting environment. Spindle speed, feed rate and depth of cut were selected for study whilst arithmetic surface roughness average $\left(R_{a}\right)$ and main cutting force component $\left(F_{C}\right)$ were treated as quality objectives characterizing machinability. For the aforementioned materials a full factorial design of experiments was conducted to exploit main effects and interactions among parameters it terms of quality objectives. The results obtained from dry turning experiments were utilized as a data set to test, train and validate a feed-forward back propagation artificial neural network for machinability prediction regarding all three materials. The work presents the results obtained from the aforementioned experimental effort under an extensive state-of-the-art survey concerning neural network technology and implementation to machining optimization problems.
\end{abstract}

Keywords: Cutting force, machinability, neural networks, surface roughness, turning.

\section{INTRODUCTION}

Machining is one among the four popular manufacturing processes, the other three being forming, casting, and joining [1]. Among these conventional machining processes, the attention has been paid to turning which is a type of a material removal operation where a cutting tool is used to remove material from a revolved raw stock aiming to produce a final product. Turning is the primary operation in metalworking industry for producing axisymmetric components. Turning produces components, which have critical features that require specific surface finish and the best possible functional behaviour. Due to inadequate knowledge of the complexity of the process and factors affecting the surface integrity in turning operation [2], an improper decision may cause high production costs and low machining quality. The proper selection of cutting tools and process parameters for achieving high cutting performance in a turning operation is a critical task [3].

In recent decades, considerable improvements were achieved in turning, enhancing machining of difficult-to-cut materials and resulting in improved machinability (better surface finish and smaller cutting forces) [4]. The forces acting on the tool are an important aspect of machining.

*Address correspondence to this author at the School of Pedagogical and Technological Education (ASPETE), Department of Mechanical Engineering, Laboratory of Manufacturing Processes and Machine Tools (LMProMaT), ASPETE Campus, GR 14121, N. Heraklion, Greece;

Tel: +30 210-2896841; Fax: +30 210 2821089; E-mail: vaxev@aspete.gr
Knowledge of the cutting forces is needed for estimation of power requirements and for the design of machine tool elements, tool-holders and fixtures, adequately rigid and free from vibration. Power consumed in metal cutting is largely converted into heat near the cutting edge of tool, and many of the economic and technical problems of machining are caused by this heating action. Moreover, the cost of machining is strongly dependent on the rate of material removal, and this cost may be reduced by increasing the cutting speed and/or the feed rate; however, there are restrictions to the speed and feed values above which the life of the tool is shortened excessively [5].

Cutting force calculation and modelling are one of the major aspects of metal cutting theory. The large number of inter-related parameters that influence the cutting forces (cutting speed, feed, depth of cut, primary and secondary cutting edge angles, rake angle, nose radius, clearance angle, cutting edge inclination angle, cutting tool wear, physical and chemical characteristics of the machined part, cutting tool (coating type, chip breaker geometry, etc.) makes the development of a proper model a very difficult task [6].

The surface roughness describes the geometry of the surface to be machined and it is interrelated with surface texture and surface integrity. The formation of surface roughness mechanism is very complicated and mainly depends on machining process [7]. Hence, it is very difficult to determine the surface roughness through analytical equations. 
Although an enormous amount of cutting force and surface roughness related data is available in machining handbooks, most of them attempt to define the relationship between a specific number of process parameters whilst keeping others constant [8]. Taking into account this observation it is not surprising that from the era of conventional machine tools to the present era of $\mathrm{CNC}$ machine tools, the prediction of cutting behaviour of processes and the optimization of machining parameters have been major areas of scientific and industrial research.

Nowadays, due to the development of computer technology, finite element and soft computing methods are being used extensively for modeling and optimization of machining processes $[9,10]$. The soft computing differs from conventional (hard) computing in that it is tolerant of imprecision, uncertainty, partial truth and approximation. Soft computing techniques include neural network (NN), fuzzy set theory, genetic algorithm (GA), simulated annealing (SA), ant colony optimization (ACO) and particle swarm optimization (PSO); see Refs. [1, 11].

Artificial Neural Networks (ANNs) are robust computing modules, currently being used in many fields of engineering to model complex relationships which are difficult to be described through physical models. ANNs have been extensively applied to model various machining operations; either conventional (turning, milling, grinding) or nonconventional [Electro-discharge machining (EDM), Abrasive water-jet machining (AWJM) etc]; see Refs [8, 12-16].

As far as turning is concerned, ANNs have been used for the prediction of cutting forces $[8,17])$, surface roughness [5, 18-21]; dimensional deviation [18], tool-wear [20], tool life [22] and process optimization [23]. Of relevant interest are also the combinations of ANN with other soft computing techniques such as GA together with Taguchi experimental design; see for example Refs. [24-28].

ANN applications in engineering are numerous and the review of them is beyond the scope of the present research; only some additional examples are noted here. Zeng in [29] presented the use of NN in mechanics whilst Sha \& Edwards in [30] discussed the application of NNs in materials science. Adeli in [31] reviewed the applications of neural networks in civil engineering whilst Petroutsatou et al. [32] as well as Nemeth [33] presented possible applications of NNs in construction. In particular, Bilgehan \& Turgut [34] applied ANN in order to predict the compressive strength of concrete. Moreover, an interesting application has been recently reported (Asteris \& Plevris [35-37], in the field of civil engineering materials. The authors using available in the literature, both experimental [38] and analytical results [39-41]) on the behaviour of anisotropic materials such as masonry, developed a neural network for the modeling of masonry under biaxial stress state. Their results show the great potential of using $\mathrm{NN}$ for the prediction of the masonry failure under biaxial compressive stress.

The present paper aims to the development of an artificial neural network capable of estimating/predicting the main cutting force $\left(F_{c}\right)$ and surface quality $\left(R_{a}\right)$. For this purpose, several Artificial Neural Network (ANN) architectures were examined for their performance in turning operation of three important engineering alloys (AISI D6 tool steel, Ti6A14V ELI titanium and $\mathrm{CuZn39Pb3}$ brass).

Note that the optimization (minimization) both of the cutting force $\left(F_{c}\right)$ and surface quality $\left(R_{a}\right)$ are crucial indicators of the improved machinability of an engineering material. Machinability is a recognizable property of a material but difficult to express quantitatively. Generally, the machinability of a material is defined in terms of the following four factors: (1) surface finish and integrity of the machined part, (2) tool life obtained, (3) force and power requirements, and (4) chip control. Therefore, good machinability indicates good surface finish and integrity, long tool life, low force and power requirements, and type of chip that does not interfere with the machining operation and is easy to collect; see Kalpakjian \& Schmid [42].

\section{ARTIFICIAL NEURAL NETWORKS (ANNS) BACK- GROUND}

\section{Structure of ANNs}

Even though there is not a single, or universally accepted, definition of ANNs, it is widely accepted that an ANN is a network of many simple processing "units" (also referred to as "elements", "nodes" or "neurons") each with a small amount of local memory and in some cases arranged in layers. Nodes are connected through communication "channels" (usually referred to as "connections", "connection weights" or "weights"). Connections bear encoded arithmetic data. Nodes process only local data and inputs brought to them through the connections. From a scientific point of view, Artificial Neural Networks (ANNs) are systems consisting of a number of processing units or elements that calculate in parallel and whose functioning is determined by the network structure, the connection weights and the processing that is carried out on the elements or the nodes [43]. These systems tend to store empirical knowledge and to make it available for use similarly to the human brain. Knowledge is acquired through learning and it is stored in the connections between neurons [44].

\section{ANN Formulation}

Formulation of ANNs is the mathematical modelling of the biological neuron networks, so that they can perform complex, and "intelligent", calculations similar to the ones performed by the human brain. Most ANN types require a "training" stage, during which connection weights are adapted regarding a set of training data. Hence, ANNs "learn" or "are trained" by examples. When trained properly, ANNs can "generalize" (e.g. predict output values) beyond the field of training data. Training algorithms commonly implemented are Gauss-Newton [45], Levenberg-Marquardt $[10,15]$, conjugate-gradients algorithms, etc. ANNs can operate on parallel computer systems, since calculations on nodes are highly independent to each other.

\section{ANN Types}

In general, a large number of ANN types have been proposed [46]. In the field of machining applications, the most commonly used types are Multilayer Perceptrons (MLP) and Radial Basis Function (RBF) networks, that belong to the Supervised learning - Feed forward ANN category, and SelfOrganizing Maps (SOM) that belong to the Unsupervised 
learning - Competitive ANN category. Fig. (1) depicts a typical architecture of a feed-forward multi-layer perceptron - MLP network. It consists of four layers; one input layer, one output layer and two hidden layers. Any node of a given layer is connected through connection weights $\left(w_{i j k}\right)$ to all nodes of the previous and the next layer. Apart from weights, biases $\left(b_{i j}\right)$ are fed to each node. A node's output is an activation function (non-linear, such as tanh or $1 /(1+\exp (-x)))$ value, whose argument is the node's sum of weights, plus the node's bias. Training stage ultimately fixes $w_{i j k}$ and $b_{i j}$ values and it is concluded when all inputs and outputs are matched with a predetermined error.

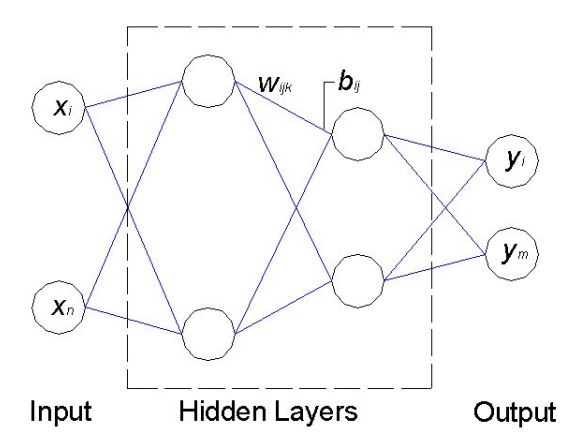

Fig. (1). Feed-forward multi-layer perceptron (MLP) with two hidden layers.

\section{Main Applications and Objectives of ANNs}

ANNs are mainly implemented in two major problem categories: (a) Classification or sorting problems, and (b) Value Prediction or Estimation of unknown functions. In classification problems, ANNs are tolerant to inaccurate data and can cope with vast training sets at which strict and fast rules fail, such as in Expert Systems. Moreover, almost any vector function defined at compact spaces can be approximated with a given accuracy by a feed forward ANN, if adequate data and resources are available; see Refs. [47, 48].

"Case" or "example" is a vector whose values are presented to all input nodes of an ANN. This vector can also include the objective or output values. An input vector value is also called "input variable" or "independent variable", while an output vector value is called "output", "objective" or "dependent variable". "Data sets" are matrices containing a number of "cases".

The main objective of ANNs is to generalize, thus to accurately perform using new data. A data set presented to an ANN at any time is called "sample" and it is divided in three subsets: training subset, which is used for parameter fitting (learning), validation subset, which is used for network architecture tuning, and test subset, which is used for accessing the generalization ability of a trained network. In the literature, the use of validation and test sets is often reversed [49, 50].

Finding an ANN that performs optimally in new cases, while it doesn't just memorize the already known cases with which it was trained, means that its performance is measured by an error function (e.g. mean square error, total absolute error, etc) when unknown -independent- data is presented to the network [49]. The validation set consists of these new cases. However, ANN efficiency is measured by a third test- set, since validation procedure may lead to ANN overfitting (data memorizing); see Markopoulos et al. [51].

Note that the origin, the development and the mathematical details for implementing the ANNs can be found in a number of reference works and/or review papers, see for example Haykin [44]; Dixit \& Dixit [9] and Chandrasekaran et al. [1]; therefore they are not discussed here.

\section{EXPERIMENTAL}

\section{Experimental Procedure}

\section{Turning}

Turning experiments were conducted using a Kern Modell D18L conventional lathe. A SECO ${ }^{\circledR}$ coated tool insert, coded as TNMG 160404 - MF2 with TP 2000 coated grade, was selected as a cutting tool for the series of experiments performed. The tool had a triangular geometry with cutting edge angle, $K_{r}=55^{\circ}$. The kinematics of the longitudinal turning process is illustrated in Fig. (2a). A 3D cutting force system was considered according to standard theory of oblique cutting [6]; see also Fig. (2b). Note that the cutting force is of the most important yet least understood operation parameters of a machining operation [52]. In general, this force is represented by three components, namely, the power component $\left(\mathrm{F}_{\mathrm{c}}\right)$, the radial component $\left(\mathrm{F}_{\mathrm{r}}\right)$ and the axial (or feed) component $\left(F_{f}\right)$ as shown in Fig. (2b). Of these three components, the greatest, normally, is the power component, which is often called the main cutting force $\left(\mathrm{F}_{\mathrm{c}}\right)$.

Note that the accurate determination of cutting forces is essential for process performance, for the evaluation of machining accuracy as well as for tool-wear estimation and for developing machinability criteria [53].

\section{Test Material}

Three engineering materials extensively used in machining operations were tested.

- A tool steel with commercial name Sverker- $3^{\circledR}$. It is a high-carbon (2.05\%), high-chromium (12.7\%) tool steel alloyed with tungsten (1.1\%) identical to AISI-D6 grade with hardness $240 \mathrm{HB}$.

- A titanium alloy, namely Ti-6Al-4V ELI; an Alpha-Beta titanium alloy which contains $6 \%$ alpha stabilizer (aluminium) and $4 \%$ beta stabilizer (vanadium) by weight. Its hardness is $326 \mathrm{HB}$. It is very similar to Ti-6Al-4V (Grade 5), with the difference that Ti-6Al-4V ELI contains reduced oxygen nitrogen, carbon and iron levels. Studies concerning the microstructure and machinability of Ti-6Al-4V alloy were reported by Arrazola et al. [54] and Vaxevanidis et al. [55].

- An industrial copper alloy, namely $\mathrm{CuZn} 39 \mathrm{~Pb} 3$ (CW614N - Brass 583) typically used for machining applications. Its hardness is $130 \mathrm{HB})$. Studies concerning the microstructure and machinability of $\mathrm{CuZn} 39 \mathrm{~Pb} 3 \mathrm{al}-$ loy were reported by Pantazopoulos [56] and Toulfatzis et al. [57]. bars.

All test materials was supplied in the form of $\varnothing 45 \mathrm{~mm}$ 


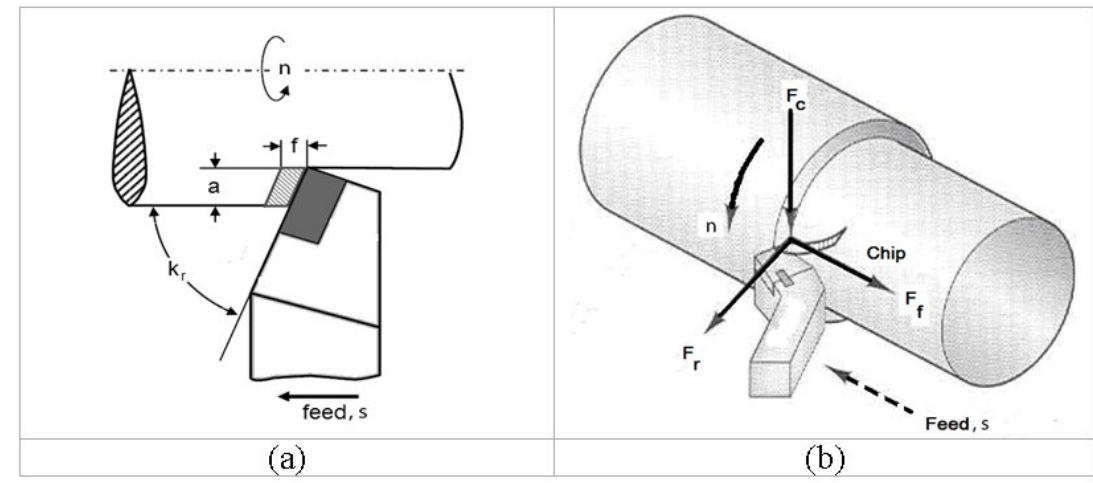

Fig. (2). (a) Kinematics of the longitudinal turning process and (b) Three-dimensional cutting force system.

\section{Measuring Techniques}

The surface texture analysis was performed using a Rank Taylor-Hobson ${ }^{\circledR}$ Surtronic 3+ profilometer equipped with the Talyprof $^{\mathbb{B}}$ software. The cut-off length was selected at 0.8 $\mathrm{mm}$ whilst 5 measurements were conducted on every pass at the longitudinal direction. Arithmetic average (or mean) surface roughness $\left(R_{a}\right)$ was selected as the representative surface quality characteristic since it is by far the most commonly used parameter in surface finish measurement and for general quality control. Despite its inherent limitations, it is easy to measure and offers a good overall description of the height characteristics of a surface profile [2].

For the cutting forces measurements a Kistler ${ }^{\mathbb{B}}$ three-axis piezoelectric dynamometer type 9257B was used. During machining, tool wear was maintained within the limit as per ISO specification and no cutting fluid was used.

\section{Experimental Results}

The experimental procedure was designed using the Taguchi method [58] which uses an orthogonal array to study the entire parametric space with performing only a limited number of experiments. For each material, the main cutting parameters (rotational speed - $\mathrm{n}, \mathrm{rpm}$, feed rate $-\mathrm{f}, \mathrm{mm} / \mathrm{rev}$ and depth of cut - a, $\mathrm{mm}$ ) were assigned on a standard L27 Orthogonal Array (OA). Three levels were specified for each of the three cutting parameters for each material. Table 1 summarizes the experimental results and the final matrix for the ANN implementation as it is explained in a next section.

It is mentioned here that Response Surface Methodology (RSM) and Taguchi's Design of Experiments (DOE) are also constitute trustworthy optimization strategies when it comes in machining but they are not presented since they are out of the scope in the present study. Research by Asiltürk \& Çunkaş [21] and Vaxevanidis et al. [59] are noted here as references for these optimization methods.

\section{MODELLING BY ARTIFICIAL NEURAL NET- WORKS (ANNs)}

\section{Neural Network's Architecture}

Two ANNs were developed in order to estimate outputs for quality characteristics $\left(F_{c}, R_{a}\right)$. Known for its capabilities on establishing neural network models, MATLAB $7.4^{\circledR}$ with associate toolboxes [60] was used for coding the algorithm. The 81 experimental data samples; see Table 1, were separated into three groups, namely, the training, the validation and the testing samples. The division of data to the training, validation and testing samples was randomly performed $(70 \%, 15 \%$, and $15 \%$, respectively. Training samples were presented to the network during training and the network was adjusted according to its error. Validation samples were utilized to assess the network's generalization capability and to halt training when generalization stopped improvement.

In general, testing samples do not affect training procedure, whilst provide also an independent measure of network performance during and after training (confirmation runs); see Markopoulos et al. [15] and Kechagias \& Iakovakis [61]). Even though standard procedure for calculating the proper number of hidden layers and neurons does not exist Kolmogorov's Theorem or Widrow Rule may be used for calculating the number of hidden neurons mainly when it comes to complicated systems [44].

The feed-forward with back-propagation learning (FFBP) architecture has been selected to analyze the performance measures. The network types which belong to this particular category, have an input layer of $X$ inputs; one, or more hidden layers with several neurons; and an output layer of $Y$ outputs. As a transfer function of the hidden layer, the hyperbolic tangent sigmoid was adopted; whereas for the output layer, a linear transfer function was implemented.

\section{ANN Topology}

The topology of the two FFBP-ANNs is shown in Figs. (3 and 4), for $F_{c}$ and $R_{a}$, respectively. The input vector consists of the four parameters [Brinell hardness (HB), rotational speed (n), feed rate (s), and depth of cut (a)]. The number of the hidden layers and the number of the neurons were selected and optimized after several trials (see Table 2 and Table 3). The best topology for $F_{c}$ ANN is the $4 \times 14 \times 1$ (one hidden layer) and for $\mathrm{R}_{\mathrm{a}}$ is the $4 \times 5 \times 15 \times 1$ (two hidden layers); see also Table $\mathbf{2}$ and Table $\mathbf{3}$, respectively.

For the selection of the NN topology, the trial and error method was used. First NNs with one hidden layer was tested but the results were vast. Then NNs with 2 hidden 
Table 1. Experimental results and matrix of the ANN implementation.

\begin{tabular}{|c|c|c|c|c|c|c|c|c|c|}
\hline & \multirow[t]{2}{*}{$\mathbf{A} / \mathbf{A}$} & \multicolumn{4}{|c|}{ Input parameters } & \multicolumn{4}{|c|}{ Objective functions - Performance measures } \\
\hline & & & & & & & Exp. & & Exp. \\
\hline Material & & $\begin{array}{c}\text { Hardness } \\
\text { (HB) }\end{array}$ & $\begin{array}{c}\text { Speed } \\
\text { n (rpm) }\end{array}$ & $\begin{array}{c}\text { Feed } \\
\text { S }(\mathrm{mm} / \mathrm{rev})\end{array}$ & $\begin{array}{c}\text { Depth of cut } \\
\text { a (mm) }\end{array}$ & $-10 \log (\mathrm{Fc})$ & $\mathbf{F}_{\mathrm{c}}(\mathbf{N})$ & $-10 \log (\mathrm{Ra})$ & $\mathbf{R}_{\mathrm{a}}(\boldsymbol{\mu m})$ \\
\hline \multirow{27}{*}{$\begin{array}{c}\text { Brass } \\
\mathrm{CuZn39Pb3}\end{array}$} & 1 & 130 & 850 & 0.15 & 1.5 & -22.9 & 195 & -2.55 & 1.8 \\
\hline & 2 & 130 & 850 & 0.15 & 1 & -21.4 & 139 & -2.64 & 1.84 \\
\hline & 3 & 130 & 850 & 0.15 & 0.5 & -18.3 & 69 & -3.03 & 2.01 \\
\hline & 4 & 130 & 850 & 0.1 & 1.5 & -21.7 & 150 & -2.30 & 1.7 \\
\hline & 5 & 130 & 850 & 0.1 & 1 & -19.9 & 99 & -2.22 & 1.67 \\
\hline & 6 & 130 & 850 & 0.1 & 0.5 & -17.4 & 55 & -1.84 & 1.53 \\
\hline & 7 & 130 & 850 & 0.06 & 1.5 & -20.5 & 113 & -2.17 & 1.65 \\
\hline & 8 & 130 & 850 & 0.06 & 1 & -18.9 & 79 & -2.12 & 1.63 \\
\hline & 9 & 130 & 600 & 0.15 & 1.5 & -22.3 & 171 & -3.30 & 2.14 \\
\hline & 10 & 130 & 600 & 0.15 & 1 & -21.3 & 138 & -2.45 & 1.76 \\
\hline & 11 & 130 & 600 & 0.15 & 0.5 & -18.6 & 73 & -2.57 & 1.81 \\
\hline & 12 & 130 & 600 & 0.06 & 1.5 & -20.3 & 109 & -2.81 & 1.91 \\
\hline & 13 & 130 & 600 & 0.06 & 1 & -18.9 & 79 & -2.69 & 1.86 \\
\hline & 14 & 130 & 420 & 0.15 & 1.5 & -22.7 & 189 & -2.50 & 1.78 \\
\hline & 15 & 130 & 420 & 0.15 & 1 & -21.1 & 130 & -2.09 & 1.62 \\
\hline & 16 & 130 & 420 & 0.15 & 0.5 & -18.6 & 74 & -2.64 & 1.84 \\
\hline & 17 & 130 & 420 & 0.06 & 1.5 & -20.3 & 108 & -2.25 & 1.68 \\
\hline & 18 & 130 & 420 & 0.06 & 1 & -18.8 & 77 & -1.52 & 1.42 \\
\hline & 19 & 130 & 420 & 0.06 & 0.5 & -16.3 & 43 & -2.50 & 1.78 \\
\hline & 20 & 130 & 420 & 0.1 & 1.5 & -21.6 & 145 & -1.58 & 1.44 \\
\hline & 21 & 130 & 420 & 0.1 & 1 & -20.3 & 108 & -1.39 & 1.38 \\
\hline & 22 & 130 & 420 & 0.1 & 0.5 & -17.7 & 59 & -1.49 & 1.41 \\
\hline & 23 & 130 & 850 & 0.06 & 0.5 & -18.0 & 64 & -1.81 & 1.52 \\
\hline & 24 & 130 & 600 & 0.06 & 0.5 & -18.1 & 65 & -1.81 & 1.52 \\
\hline & 25 & 130 & 600 & 0.1 & 1.5 & -21.7 & 149 & -2.30 & 1.7 \\
\hline & 26 & 130 & 600 & 0.1 & 1 & -20.3 & 109 & -2.25 & 1.68 \\
\hline & 27 & 130 & 600 & 0.1 & 0.5 & -17.7 & 59 & -1.52 & 1.42 \\
\hline \multirow{7}{*}{$\begin{array}{l}\text { AISI D6 tool } \\
\text { steel }\end{array}$} & 28 & 240 & 850 & 0.15 & 1.5 & -27.2 & 536 & -4.21 & 2.64 \\
\hline & 29 & 240 & 850 & 0.15 & 1 & -25.0 & 320 & -3.42 & 2.2 \\
\hline & 30 & 240 & 850 & 0.15 & 0.5 & -21.3 & 136 & -2.62 & 1.83 \\
\hline & 31 & 240 & 850 & 0.1 & 1.5 & -25.3 & 344 & -10.6 & 11.5 \\
\hline & 32 & 240 & 850 & 0.1 & 1 & -22.6 & 184 & -8.85 & 7.69 \\
\hline & 33 & 240 & 850 & 0.1 & 0.5 & -17.4 & 56 & -1.30 & 1.35 \\
\hline & 34 & 240 & 850 & 0.06 & 1.5 & -24.0 & 256 & -8.67 & 7.37 \\
\hline
\end{tabular}


(Table 1) contd....

\begin{tabular}{|c|c|c|c|c|c|c|c|c|c|}
\hline & \multirow[t]{2}{*}{$\mathbf{A} / \mathbf{A}$} & \multicolumn{4}{|c|}{ Input parameters } & \multicolumn{4}{|c|}{ Objective functions - Performance measures } \\
\hline & & & & & & & Exp. & & Exp. \\
\hline Material & & $\begin{array}{c}\text { Hardness } \\
\text { (HB) }\end{array}$ & $\begin{array}{c}\text { Speed } \\
\text { n (rpm) }\end{array}$ & $\begin{array}{c}\text { Feed } \\
\mathrm{S}(\mathrm{mm} / \mathrm{rev})\end{array}$ & $\begin{array}{c}\text { Depth of cut } \\
\text { a (mm) }\end{array}$ & $-10 \log (\mathrm{Fc})$ & $\mathbf{F}_{\mathrm{c}}(\mathbf{N})$ & $-10 \log (\mathrm{Ra})$ & $\mathbf{R}_{\mathbf{a}}(\boldsymbol{\mu m})$ \\
\hline \multirow{20}{*}{$\begin{array}{l}\text { AISI D6 tool } \\
\text { steel }\end{array}$} & 35 & 240 & 850 & 0.06 & 1 & -22.0 & 160 & -6.98 & 4.99 \\
\hline & 36 & 240 & 850 & 0.06 & 0.5 & -21.3 & 138 & -5.64 & 3.67 \\
\hline & 37 & 240 & 600 & 0.15 & 1.5 & -27.2 & 536 & -12.9 & 19.8 \\
\hline & 38 & 240 & 600 & 0.15 & 1 & -25.6 & 364 & -13.0 & 20.01 \\
\hline & 39 & 240 & 600 & 0.15 & 0.5 & -21.8 & 152 & -12.8 & 19.4 \\
\hline & 40 & 240 & 600 & 0.1 & 1.5 & -26.3 & 428 & -12.9 & 19.87 \\
\hline & 41 & 240 & 600 & 0.1 & 1 & -24.3 & 272 & -11.9 & 15.73 \\
\hline & 42 & 240 & 600 & 0.1 & 0.5 & -19.8 & 96 & -11.4 & 14.07 \\
\hline & 43 & 240 & 600 & 0.06 & 1.5 & -24.5 & 284 & -8.24 & 6.67 \\
\hline & 44 & 240 & 600 & 0.06 & 1 & -22.6 & 184 & -8.06 & 6.4 \\
\hline & 45 & 240 & 600 & 0.06 & 0.5 & -18.5 & 72 & -8.10 & 6.47 \\
\hline & 46 & 240 & 420 & 0.15 & 1.5 & -27.6 & 584 & -12.8 & 19.3 \\
\hline & 47 & 240 & 420 & 0.15 & 1 & -25.7 & 376 & -12.4 & 17.4 \\
\hline & 48 & 240 & 420 & 0.15 & 0.5 & -21.6 & 146 & -11.4 & 13.87 \\
\hline & 49 & 240 & 420 & 0.1 & 1.5 & -26.5 & 452 & -11.2 & 13.27 \\
\hline & 50 & 240 & 420 & 0.1 & 1 & -23.9 & 246 & -11.9 & 15.53 \\
\hline & 51 & 240 & 420 & 0.1 & 0.5 & -20.4 & 112 & -11.1 & 13 \\
\hline & 52 & 240 & 420 & 0.06 & 1.5 & -24.1 & 260 & -8.28 & 6.73 \\
\hline & 53 & 240 & 420 & 0.06 & 1 & -22.7 & 188 & -8.45 & 7 \\
\hline & 54 & 240 & 420 & 0.06 & 0.5 & -18.3 & 68 & -11.9 & 15.53 \\
\hline \multirow{14}{*}{ Ti-6Al-4V } & 55 & 326 & 850 & 0.1 & 0.5 & -21.2 & 132 & -1.46 & 1.4 \\
\hline & 56 & 326 & 850 & 0.1 & 1 & -23.8 & 240 & -2.04 & 1.6 \\
\hline & 57 & 326 & 850 & 0.1 & 1.5 & -25.1 & 330 & -1.52 & 1.42 \\
\hline & 58 & 326 & 850 & 0.18 & 0.5 & -23.0 & 200 & -1.03 & 1.27 \\
\hline & 59 & 326 & 850 & 0.18 & 1 & -25.4 & 352 & -2.22 & 1.67 \\
\hline & 60 & 326 & 850 & 0.18 & 1.5 & -26.9 & 500 & -4.14 & 2.6 \\
\hline & 61 & 326 & 850 & 0.33 & 0.5 & -24.5 & 288 & -8.40 & 6.93 \\
\hline & 62 & 326 & 850 & 0.33 & 1 & -27.4 & 562 & -10.9 & 12.47 \\
\hline & 63 & 326 & 850 & 0.33 & 1.5 & -29.0 & 800 & -11.6 & 14.73 \\
\hline & 64 & 326 & 600 & 0.1 & 0.5 & -20.7 & 120 & -10.3 & 10.93 \\
\hline & 65 & 326 & 600 & 0.1 & 1 & -23.5 & 226 & -10.5 & 11.37 \\
\hline & 66 & 326 & 600 & 0.1 & 1.5 & -25.0 & 318 & -8.12 & 6.49 \\
\hline & 67 & 326 & 600 & 0.18 & 0.5 & -22.6 & 182 & -4.75 & 2.99 \\
\hline & 68 & 326 & 600 & 0.18 & 1 & -25.4 & 350 & -4.06 & 2.55 \\
\hline
\end{tabular}


(Table 1) contd....

\begin{tabular}{|c|c|c|c|c|c|c|c|c|c|}
\hline & $\mathbf{A} / \mathbf{A}$ & \multicolumn{4}{|c|}{ Input parameters } & \multicolumn{4}{|c|}{ Objective functions - Performance measures } \\
\hline Material & & $\begin{array}{l}\text { Hardness } \\
\text { (HB) }\end{array}$ & $\begin{array}{c}\text { Speed } \\
\text { n (rpm) }\end{array}$ & $\begin{array}{c}\text { Feed } \\
\text { S (mm/rev) }\end{array}$ & $\begin{array}{c}\text { Depth of cut } \\
\text { a (mm) }\end{array}$ & $-10 \log (F c)$ & $F_{c}(N)$ & $-10 \log (\mathrm{Ra})$ & $\mathbf{R}_{\mathrm{a}}(\boldsymbol{\mu} \mathbf{m})$ \\
\hline \multirow{10}{*}{ Ti-6Al-4V } & 69 & 326 & 600 & 0.18 & 1.5 & -27.0 & 502 & -5.97 & 3.96 \\
\hline & 71 & 326 & 600 & 0.33 & 1 & -27.3 & 538 & -9.50 & 8.93 \\
\hline & 72 & 326 & 600 & 0.33 & 1.5 & -28.8 & 760 & -9.63 & 9.2 \\
\hline & 73 & 326 & 420 & 0.1 & 0.5 & -21.4 & 140 & -3.40 & 2.19 \\
\hline & 74 & 326 & 420 & 0.1 & 1 & -24.1 & 258 & -3.40 & 2.19 \\
\hline & 77 & 326 & 420 & 0.18 & 1 & -26.1 & 410 & -5.37 & 3.45 \\
\hline & 78 & 326 & 420 & 0.18 & 1.5 & -27.5 & 570 & -5.58 & 3.62 \\
\hline & 79 & 326 & 420 & 0.33 & 0.5 & -24.5 & 284 & -9.21 & 8.34 \\
\hline & 80 & 326 & 420 & 0.33 & 1 & -27.5 & 564 & -9.12 & 8.17 \\
\hline & 81 & 326 & 420 & 0.33 & 1.5 & -29.2 & 840 & -9.00 & 7.95 \\
\hline
\end{tabular}

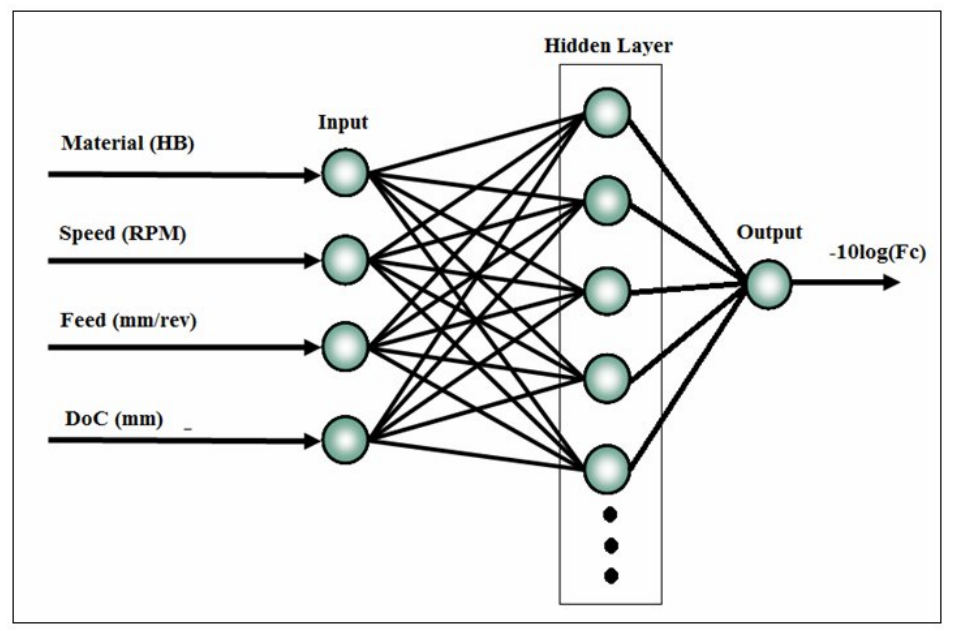

Fig. (3). Topology of the optimized FFBP ANN for $F_{c}$ prediction.

layers we applied and good results were obtained. Note also, that the use of two different (discrete) NNs leads to better results, especially for the case of $R_{a}$ quality indicator. Moreover, "Best val. Perf." was the criterion in order to select the "best" architecture.

Levenberg-Marquardt algorithm (TRAINLM) was utilized to train the networks; whilst mean square error (MSE) was used as the objective function. It is noted here that Mean Squared Error (MSE) is the average squared difference be- tween network output values and target values. Low values for Mean Squared Error indicate less error; consequently, zero value of MSE means no error at all.

\section{ANNs Performance Results}

\section{Training Stage and Validation Performance}

The best validation performance and the training stage for each one of the two FFBP-ANNs addressed $F_{c}$ and $R_{a}$ are shown in Fig. (5a) and Fig. (5b), respectively. 


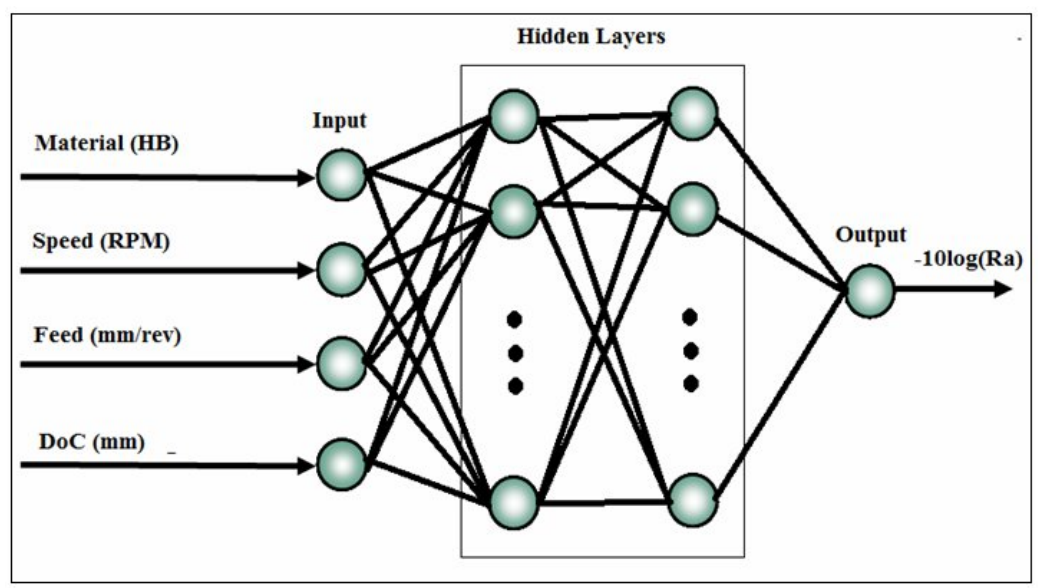

Fig. (4). Topology of the optimized FFBP ANN for $\mathrm{R}_{\mathrm{a}}$ prediction.

Table 2. Neural network topologies tested for ANN architecture $-F_{c}$.

\begin{tabular}{|c|c|c|c|c|}
\hline & $\mathbf{4 x 1 2 \times 1}$ & $\mathbf{4 x 1 3 \times 1}$ & $\mathbf{4 x 1 4 \times 1}$ & $\mathbf{4 x 1 5 \times 1}$ \\
\hline \hline Training & 0.999 & 0.993 & $\mathbf{0 . 9 9 4}$ & 0.995 \\
\hline Validation & 0.916 & 0.939 & $\mathbf{0 . 9 2 4}$ & $\mathbf{0 . 9 7 2}$ \\
\hline Test & 0.941 & 0.948 & $\mathbf{0 . 9 7 6}$ & 0.967 \\
\hline All & 0.996 & 0.970 & $\mathbf{0 . 4 8 0}$ & 0.967 \\
\hline Best val. perf. & 1.683 & 0.593 & $\mathbf{3}$ & 1 \\
\hline epoch & 4 & 5 & \\
\hline
\end{tabular}

Table 3. Neural network topologies tested for ANN architecture $-\mathbf{R}_{\mathbf{a}}$.

\begin{tabular}{|c|c|c|c|c|}
\hline Training & 0.998 & 0.994 & 0.999 & 1 \\
\hline Test & 0.724 & 0.796 & 0.854 & 0.489 \\
\hline All & 0.853 & 0.919 & 0.930 & 0.824 \\
\hline epoch & 6 & 5 & 15 & 9 \\
\hline
\end{tabular}

\section{ANNs Correlation}

Another indicator used for performance evaluation for network efficiency is the regression coefficient, $(R)$. Regression values measure the correlation between output values and targets. The acquired results for both ANNs showed a very good correlation between output values and targets during training. Specifically, for the first ANN ( $F_{c}$ prediction) the determination coefficients $(\mathrm{R})$ for training, testing and validation data were found $0.994,0.924$ and 0.9972 respec- tively; whereas for the second ANN ( $R_{a}$ prediction) the determination coefficients $(\mathrm{R})$ for training, testing and validation data were found $0.994,0.807$ and 0.796 , respectively; see Fig. (5a) and Fig. (5b).

\section{CONCLUSION}

Cutting forces developed during machining processes and surface roughness of machined parts are of major importance for both industrial applications and academic research. 

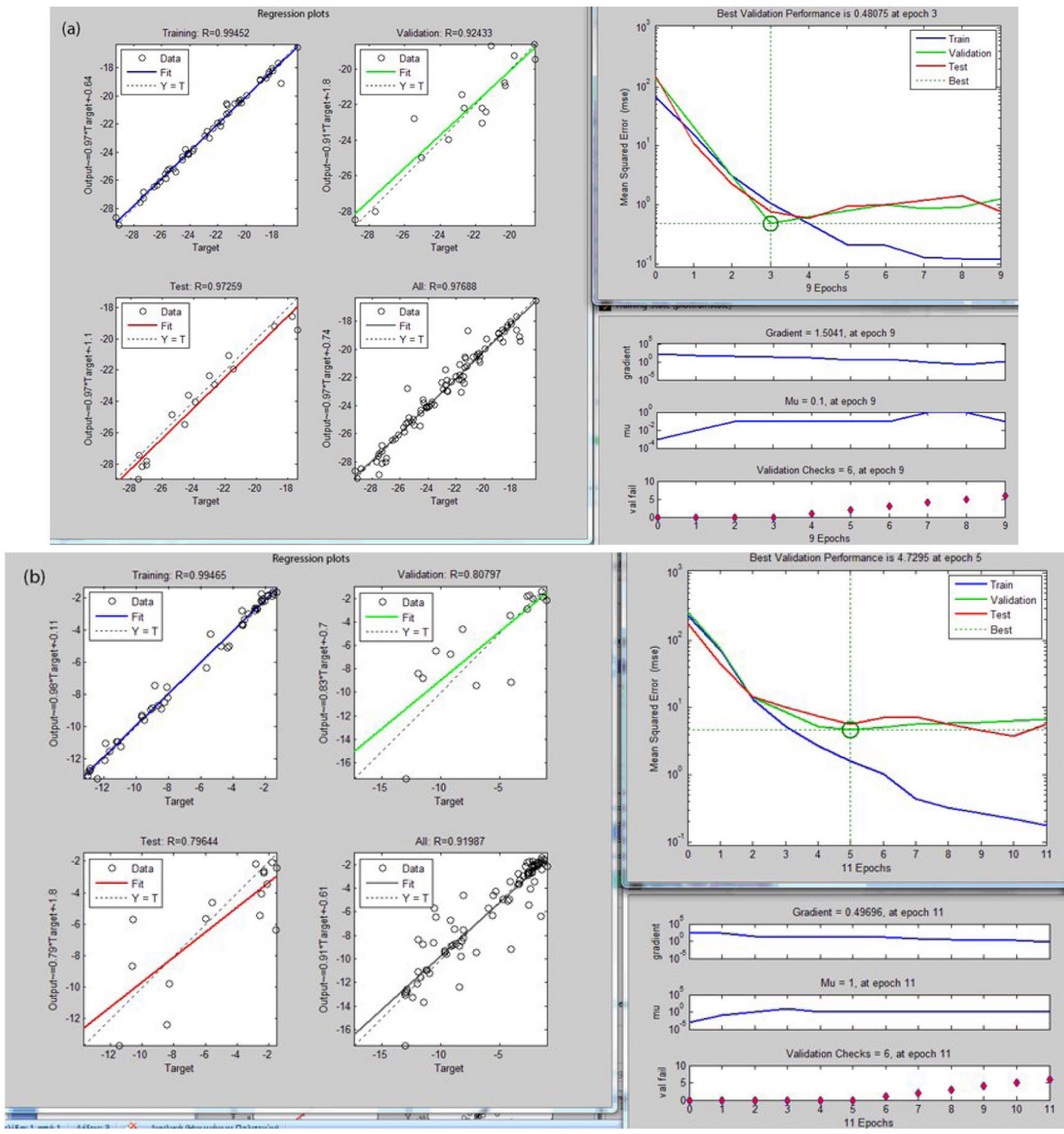

Fig. (5). Performance and training states: (a) for $F_{c}$, (b) for $R_{a}$.

Through the specification of such quality objectives, process performance and machinability of materials may be efficiently optimized. Artificial Neural Networks provide robust solutions when studying criteria reflecting machinability and quality. However, noise factors that occur during actual machining experimentation may strongly affect process results, hence making computational models and optimization modules prone to errors. Nevertheless, accuracy and reliability of results are two main benefits of soft computing techniques such artificial neural networks (ANNs).
Through the implementation of the ANN approach, main cutting force $\left(F_{c}\right)$ and average surface roughness $\left(R_{a}\right)$ were investigated during the longitudinal turning of AISI D6 tool steel, Ti6A14V ELI titanium and CuZn39Pb3 brass specimens.

The neural networks proposed were trained with experimental data acquired from actual experiments. The best performance was obtained from the ones with the FFBP architecture and topologies $4 \times 14 \times 1$ (one hidden layer) for $\mathrm{F}_{\mathrm{c}}$ $\mathrm{ANN}$ and $4 \times 5 \times 15 \times 1$ (two hidden layers) for $\mathrm{R}_{\mathrm{a}} \mathrm{ANN}$, respec- 
tively. The results obtained indicate that the proposed modelling approach could be effectively used to accurately predict the main cutting force component and the mean surface roughness during turning of AISI D6 tool steel, Ti6A14V ELI titanium and $\mathrm{CuZn} 39 \mathrm{~Pb} 3$ brass thus supporting decision making during process planning and providing a possible way to avoid time- and money-consuming experiments.

\section{CONFLICT OF INTEREST}

The authors confirm that this article content has no conflict of interest.

\section{ACKNOWLEDGEMENTS}

The authors are grateful to Dipl.-Ing. J. Sideris, Director of Uddelholm Greece s.a. for the supply of AISI D6 tool steel and to Dr.-Ing. G.A. Pantazopoulos of ELKEME Hellenic Research Centre for Metals s.a for the supply of $\mathrm{CuZn} 39 \mathrm{~Pb} 3$ brass specimens. They also wish to thank Mr. N. Melissas, technician at NTUA for performing the cutting experiments and Dr.-Ing. P. Kostazos, Assistant at NTUA for helping with the cutting forces measurements.

\section{REFERENCES}

[1] M. Chandrasekaran, M. Muralidhar, C.M. Krishna, and U.S. Dixit, "Application of soft computing techniques in machining performance prediction and optimization: a literature review", International. Journal of Advanced Manufacturing Technology, vol. 46, no. 5-8, pp. 445-464, 2010.

[2] P. Petropoulos, C.N. Pandazaras, and J.P. Davim, "Surface Texture Characterization and Evaluation Related to Machining", in Surface Integrity in Machining (editor Davim, J.P.), Springer, pp. 37-66, 2010 .

[3] J.P. Davim, V.N. Gaitonde, and S.R. Karnik, "Investigations into the effect of cutting conditions on surface roughness in turning of free machining steel by ANN models", Journal of Materials Processing Technology, vol. 205, no. 1-3, pp. 16-23, 2008.

[4] N.M. Vaxevanidis, N. Galanis, G.P. Petropoulos, N. Karalis, P. Vasilakakos, and J. Sideris, "Surface Roughness Analysis in High Speed-Dry Turning of Tool Steel", Proceedings of ESDA 2010: 10th Biennial ASME Conference on Engineering Systems Design and Analysis, July 12-14, Istanbul, Turkey. (paper ESDA 201024811), 2010.

[5] V.S. Sharma, S. Dhiman, R. Sehgal, and S.K. Sharma, "Estimation of cutting forces and surface roughness for hard turning using neural networks", Journal of Intelligent Manufacturing, vol. 19, pp. 473-483, 2008.

[6] G. Boothroyd, and W. Knight, Fundamentals of Machining and Machine Tools, CRC Press, 2005.

[7] G.P. Petropoulos, N.M. Vaxevanidis, C.N. Pandazaras, and A.A.Antoniadis, "Multi-parameter identification and control of turned surface textures", International Journal of Advanced Manufacturing Technology, vol. 29, pp. 118-128, 2006.

[8] T. Szecsi, "Cutting force modeling using artificial neural networks", Journal of Materials Processing Technology, vol. 92-93, pp. 344-349, 1999.

[9] P.M. Dixit, and U.S. Dixit, Modeling of metal forming and machining processes: by finite element and soft computing methods, Springer, London, 2008.

[10] N.A. Fountas, I. Ntziantzias, J. Kechagias, A. Koutsomichalis, J.P. Davim, and N.M. Vaxevanidis, "Prediction of Cutting Forces during Turning PA66 GF-30 Glass Fiber Reinforced Polyamide by Soft Computing Techniques", Materials Science Forum, vol. 766, pp. $37-58,2013$

[11] N.A. Fountas, and N.M. Vaxevanidis, "Modified Virus Evolutionary Genetic Algorithm for Rough Machining Optimization of Sculptured Surfaces", Annals of the Faculty of Engineering Hunedoara, vol. XI, no. 3, pp. 283-288, 2013.
[12] G. Dini, "Literature database on applications of artificial intelligence methods in manufacturing engineering", Annals of the CIRP, vol. 46, no. 2, pp. 681-690, 1997.

[13] T.M.A. Maksoud, M.R. Atia, and M.M. Koura, "Applications of artificial intelligence to grinding operations via neural networks", Machining Science and Technology, vol. 7, no. 3, pp. 361-387, 2003.

[14] E.O. Ezugwu, D.A. Fadare, J. Bonney, R.B. Da Silva, and W.F. Sales,"Modeling the correlation between cutting and process parameters in high-speed machining of Inconel 718 alloy using an artificial neural network", International Journal of Machine Tools and Manufacture, vol. 45, pp. 1375-1385, 2005.

[15] A. Markopoulos, N.M. Vaxevanidis, G. Petropoulos, and D.E. Manolakos,"Artificial neural networks modeling of surface finish in electro-discharge machining of tool steels, Proceedings of ESDA2006: 8th Biennial ASME Conference on Engineering Systems Design and Analysis, July 4-7, Torino; Italy (paper ESDA2006-95609), 2006.

[16] N.M. Vaxevanidis, A. Markopoulos, and G. Petropoulos, "Artificial neural network modelling of surface quality characteristics in abrasive water jet machining of trip steel sheet", chapter 5 in Artificial Intelligence in Manufacturing Research, (ed. J. P. Davim), Nova Publishers, pp. 79-99, 2010.

[17] W. Hao, X. Zhu, X. Li, and G. Turyagyenda, "Prediction of cutting force for self-propelled rotary tool using artificial neural networks", Journal of Materials Processing Technology, vol. 180, pp. 23-29. 2006.

[18] K.A. Risbood, U.S. Dixit, and A.D. Sahasrabudhe, "Prediction of surface roughness and dimensional deviation by measuring cutting forces and vibrations in turning process", Journal of Materials Processing Technology, vol. 132, pp. 203-214, 2003.

[19] Z.W. Zhong, L.P. Khoo, and S.T. Han, Prediction of surface roughness of turned surfaces using neural networks", International Journal of Advanced Manufacturing Technology, vol. 28, no. 7-8, pp. 688-693, 2006.

[20] T. Özel, and Y. Karpat, "Predictive modelling of surface roughness and tool wear in hard turning using regression and neural networks", International Journal of Machine Tools and Manufacture, vol. 45, pp. 467-479, 2005.

[21] I. Asiltürk, and M. Çunkaş, "Modeling and prediction of surface roughness in turning operations using artificial neural network and multiple regression method", Expert Systems with Applications, vol. 38 , no. 5 , pp. 5826-5832, 2011.

[22] D.K. Ojha, and U.S. Dixit, "An economic and reliable tool life estimation procedure for turning", International Journal of Advanced Manufacturing Technology, vol. 26, pp. 726-732, 2005.

[23] U.Zuperl, and F. Cus, "Optimization of cutting conditions during cutting by using neural networks", Robotics and Computer Integrated Manufacturing, vol. 19, pp. 189-199, 2003.

[24] M. Sedighi, and D. Afshari, "Creep feed grinding optimization by an integrated GA-NN system", Journal of Intelligent Manufacturing, vol. 21, no. 6, pp. 657-663, 2009.

[25] T.V. Sibalija, S.Z. Petronic, V.D. Majstorovic, and A. Milosavljevic, Modelling and optimisation of laser shock peening using an integrated simulated annealing-based method", International Journal of Advanced Manufacturing Technology, vol. 73, no. 5-8, pp. 1141-1158, 2014.

[26] T.V. Sibalija, and V.D. Majstorovic, "An integrated approach to optimize parameter design of multi-response processes based on Taguchi method and artificial intelligence". Journal of Intelligent Manufacturing, vol. 23, no. 5, pp. 1511-1528, 2012.

[27] T.V. Sibalija, and V.D. Majstorovic, "An integrated simulated annealing-Based method for robust multiresponse process optimization", International Journal of Advanced Manufacturing Technology, vol. 59, no. 9-12, pp. 1227-1244, 2012.

[28] N.M. Vaxevanidis, N.A. Fountas, J.D. Kechagias, and D.E. Manolakos, "Cutting forces modeling and optimization in turning AISI D6 tool steel through experimental design analysis and soft computing", IAENG Transactions on Engineering Sciences - Special Issue of the International MultiConference of Engineers and Computer Scientists, IMECS 2013 and World Congress on Engineering, WCE 2013, pp. 151-160, 2014.

[29] P. Zeng, "Neural computing in mechanics", Applied Mechanics Reviews, vol. 51, no. 2, pp. 173-197, 1998. 
[30] W. Sha, and K.L. Edwards, "The use of artificial neural networks in materials science based research", Materials and Design, vol. 28, no. 6, pp. 1747-1752, 2007.

[31] H. Adeli, "Neural networks in civil engineering: 1989-2000", Computer-Aided Civil and Infrastructure Engineering, vol.16, no. 2, pp. 126-142, 2001.

[32] K. Petroutsatou, E. Georgopoulos, S. Lambropoulos, and J.P Pantouvakis, "Early cost estimating of road tunnel construction using neural networks", Journal of Construction Engineering and Management, vol. 138, no. 6, pp. 679-687, 2012.

[33] P. Németh, "Application possibilities of artificial neural networks in the construction industry", Proceedings 2014 International Conference on Computational Science and Computational Intelligence, vol. 1, pp. 437-439, 2014.

[34] M. Bilgehan, and P. Turgut, "Artificial Neural Network Approach to Predict Compressive Strength of Concrete through Ultrasonic Pulse Velocity", Research in Nondestructive Evaluation, vol. 21, no. 1, pp. 1-17, 2010.

[35] P.G. Asteris, and V. Plevris, "Neural Network Approximation of the Masonry Failure Under Biaxial Compressive Stress", Proc. SEECCM III - 3rd South-East European Conference on Computational Mechanics, M. Papadrakakis, M. Kojic, I. Tuncer (eds.), Kos Island, Greece, 12-14 June 2013.

[36] V. Plevris, and P.G. Asteris, "Modeling of masonry failure surface under biaxial compressive stress using Neural Networks", Construction and Building Materials, vol. 55, pp. 447-461, 2014.

[37] V. Plevris, and P. Asteris, "Modeling of Masonry Compressive Failure Using Neural Networks", Proceedings of the International Conference on Engineering and Applied Sciences Optimization (OPT-i), Kos, 4-6 June, 2014, pp. 2843-2860, 2014.

[38] A.W. Page, "A biaxial failure criterion for brick masonry in the tension-tension range", The International Journal of Masonry Construction, vol. 1, pp. 26-30, 1981.

[39] C.A. Syrmakezis, and P.G. Asteris, "Masonry Failure Criterion Under Biaxial Stress State", Journal of Materials in Civil Engineering; American Society of Civil Engineers (ASCE), vol. 13, no.1, pp. 58-64, 2001.

[40] P.G. Asteris, "A simple heuristic algorithm to determine the set of closed surfaces of the cubic tensor polynomial", The Open Applied Mathematics Journal, vol. 4, pp. 1-5, 2010.

[41] P.G. Asteris, "Unified Yield Surface for the Nonlinear Analysis of Brittle Anisotropic Materials", Nonlinear Science Letters A, vol.4, no. 2, pp. 46-56, 2013.

[42] S. Kalpakjian and S.R. Schmid, Manufacturing Processes for Engineering Materials, $5^{\text {th }}$ ed., Prentice Hall, 2007.

[43] A.İ. Sönmez, A. Baykasoğlu, T. Dereli, and İ.H. Filiz, "Dynamic optimization of multi-pass milling operations via geometric programming", International Journal of Machine Tools and Manufacture, vol. 39, pp. 297-320, 1999.

[44] S. Haykin, Neural networks, a comprehensive foundation, New Jersey, Prentice Hall, 1999.

[45] P.E. Gill, W. Murray and M.H. Wright, Practical Optimization, London. Academic Press, 1981.

[46] A.K. Jain, J. Mao, and K.M. Mohiuddin, "Artificial neural networks: a tutorial”, IEEE Computer, vol. 29, no. 3, pp.31-44, 1996.
[47] H.T. Siegelmann, and E.D. Sontag, "Turing Computability with Neural Networks", Applied Mathematics Letters, vol. 4, pp. 77-80, 1999.

[48] J. Sima, and P.Orponen, "Computing with continuous-time Liapunov systems", Proceedings of the $33^{\text {rd }}$ annual ACM symposium on Theory of computing - STOC '01, Heraklion, Crete, Greece, July 06 - 08, pp. 722-731, 2001.

[49] C.M. Bishop, Neural Networks for Pattern Recognition, Oxford, Oxford University Press, 1995.

[50] B.D. Ripley, Pattern Recognition and Neural Networks, Cambridge, Cambridge University Press, 1996.

[51] A. Markopoulos, D.E. Manolakos, and N.M. Vaxevanidis, "Artificial Neural Network Models for the Prediction of Surface Roughness in Electrical Discharge Machining", Journal of Intelligent Manufacturing, vol. 19, pp. 283-292, 2008.

[52] V.P. Astakhov, and X. Xiao, “A Methodology for Practical Cutting Force Evaluation based on the Energy spent in the Cutting System", Machining Science and Technology, vol. 12, no. 3, pp. 325347, 2008.

[53] J.P. Davim, and L. Figueira, "Machinability evaluation in hard turning of cold work tool steel (D2) with ceramic tools using statistical techniques", Materials and Design, vol. 28, no. 4, pp. 11861191, 2007.

[54] P.J. Arrazola, A. Garay, L.M. Iriarte, M. Armendia, S. Marya, and F. Le Maitre, "Machinability of titanium alloys (Ti6Al4V and Ti555.3)", Journal of Materials Processing Technology, vol. 209, pp. 2223-2230, 2009.

[55] N.M. Vaxevanidis, N.A. Fountas, J. Kechagias, and D.E. Manolakos, "Estimation of main Cutting Force and Surface Roughness in turning of Ti-6Al-4V titanium alloy using Design of Experiments and Artificial Neural Networks", Proceedings of the International Conference on Engineering and Applied Sciences Optimization (OPT-i), Kos, 4-6 June, 2014, pp. 2889-2906, 2014.

[56] G. Pantazopoulos, "Leaded brass rods C 38500 for automatic machining operations: a technical report", Journal of Materials Engineering and Performance, vol. 11, pp.402-407, 2002.

[57] A.I. Toulfatzis, G.A. Pantazopoulos, and A.S. Paipetis, "Fracture behavior and characterization of lead-free brass alloys for machining applications", Journal of Materials Engineering and Performance, vol. 23, no. 9, pp. 3193-3206, 2014.

[58] G. Taguchi, Introduction to quality engineering, Asian Productivity Organization, Tokyo, 1990.

[59] N.M. Vaxevanidis, N.A. Fountas, J. Kechagias, and D.E. Manolakos, "Estimation of Main Cutting Force and Mean Surface Roughness in Turning of AISI D6 Tool Steel using Design of Experiments and Artificial Neural Networks", chapter 9 in $M A C H I N-$ ING: Operations, Technology and Management, (ed. J.P. Davim), Nova Publishers, pp. 159-187, 2013.

[60] H. Demuth and M. Beale, Neural networks toolbox for use with Matlab - User's guide. The MathWorks, Inc., 2001.

[61] J. Kechagias, and V. Iakovakis, "A neural network solution for LOM process performance", International Journal of Advanced Manufacturing Technology, vol. 43, no. 11, pp. 1214-1222, 2009.

(C) Vaxevanidis et al.; Licensee Bentham Open.

This is an open access article licensed under the terms of the Creative Commons Attribution Non-Commercial License (http://creativecommons.org/licenses/by-nc/3.0/) which permits unrestricted, non-commercial use, distribution and reproduction in any medium, provided the work is properly cited. 